\title{
Desagrarización del empleo femenino rural y tiempos de trabajo en el Perú
}

\author{
Sulema Loayza Alatrista \\ Universidad Nacional Mayor de San Marcos \\ suleloayza@yahoo.com
}

\begin{abstract}
RESUMEN
El empleo rural en el país está enfrentando en los últimos años transformaciones estructurales que tienen que ver con el proceso de desagrarización del campo, en el contexto de la globalización y penetración de la economía de mercado, en un mundo que registra mayores demandas de alimentos. La desagrarización ocupacional del medio rural en el Perú registra una participación relevante de la mujer en tareas remuneradas no agrarias, en la creciente actividad agroindustrial instalada principalmente en los valles de la costa.

En el presente artículo se busca identificar los procesos y las formas cómo se viene dando la diversificación ocupacional no agraria de la mujer rural en el valle de Motupe, Lambayeque, se establecen los condicionantes socio culturales y económicos que impulsan a la mujer a vender su fuerza de trabajo en actividades productivas no agrarias, afrontando retos que tienen que ver con restricciones socio culturales a su capacidad productiva y reconocimiento económico y social; adicionalmente, se estudia la complejización del entramado de los tiempos de trabajo productivo con los de cuidados doméstico familiares.
\end{abstract}

Palabras clave: Desagrarización, empleo femenino rural, tiempos de trabajo.

\section{De-agrarization of rural female employment and working hours in Peru}

\begin{abstract}
Rural employment in the country is facing in recent years structural changes that have to do with the process of de-agrarization of the fi land, in the context of globalization and market economy penetration, in a world that registers an increasing demand for food. The occupational de-agrarization of rural areas in Peru registers a significant participation of women in non-agricultural remunerated tasks, in the growing agroindustrial activity located mainly in the coastal valleys.

In this article we seek to identify the processes and ways in which the non-agrarian occupational diversification of rural women in the Motupe-Lambayeque valley has taken place, establishing the socio-cultural and economic conditions that drive women to sell their labor to non-agrarian production activities, facing challenges that have to do with socio-cultural restrictions on their productive capacity and economic and social recognition; in addition to the complexity of the network of working hours and household chores.
\end{abstract}

KEYwORDs: De-agrarization, rural female employment, working hours. 


\section{Introducción}

E 1 presente estudio pretende explicar los condicionantes socioculturales y económicos de la diversificación del empleo no agrario de la mujer rural, que se viene dando en términos desiguales, en el contexto de la economía de mercado mundializada y que la actividad agroindustrial viene impulsando en el valle de Motupe, Lambayeque; asimismo, se busca profundizar el conocimiento de los aspectos limitantes para el acrecentamiento de las capacidades y potencialidades productivas y personales de las mujeres trabajadoras, esencialmente las restricciones a su educación, heredadas de las concepciones asalariadas tradicionales, también se analiza el entramado conflictivo de los tiempos de trabajo productivo y los de cuidados domésticos, que todavía recaen predominantemente en el ámbito de responsabilidades que asume la mujer rural.

La revisión de la documentación existente, de fuentes nacionales como externas, contrastada con las indagaciones de campo realizadas, confirman la validez de las hipótesis de trabajo planteadas, tanto en lo referente a que la mujer rural de Motupe opta por diversificar sus ocupaciones productivas en actividades no agrícolas, apartándose de la función de ayuda familiar agraria tradicional, como una estrategia para mejorar sus ingresos familiares, así mismo, encontramos que los vínculos de la mujer rural con actividades económicas no agrarias se dan en forma selectiva, generalmente en función de sus ingresos económicos familiares, su nivel educativo y su edad. Por otro lado, y conforme a lo planteado inicialmente, hemos verificado que los cambios en el orden temporal del trabajo de la mujer rural le generan serias dificultades para compaginar sus tiempos de trabajo con sus tiempos de cuidados domésticos, problematizándole la conducción en su organización familiar, obligándole a extremar esfuerzos ante una percepción agobiante del tiempo, a lo que se agrega la desventajosa posición de la mujer rural, trabajadora asalariada de Motupe, cuyo trabajo productivo tiene un impacto relativo y diferenciado en el reconocimiento de sus derechos laborales, así como en sus ingresos económicos y reconocimiento social.

Buscamos explicar los procesos y formas cómo la mujer rural ingresa al trabajo asalariado agroindustrial, examinar su participación en un mercado de trabajo que está experimentando un paulatino proceso de desagrarización y cómo se insertan los cambios que se observan en el orden de la temporalidad social del trabajo asalariado femenino, considerando la importancia que en la organización de los tiempos tiene para la mujer la relación entre el tiempo de trabajo productivo y el de cuidados doméstico familiares y, consiguientemente, el de las relaciones de género. Asimismo, se trata de examinar la influencia de la educación como trasmisora no solo de conocimientos de tipo instrumental, sino, de un sistema de valores que conforman las expectativas del individuo, las mismas que devienen como elemento fundamental del rechazo "genérico de la actividad agraria», que las generaciones jóvenes del presente manifiestan.

\section{Consideraciones teóricas y antecedentes}

La dinámica agraria capitalista en el Perú avanzó lentamente durante los años 80 y registró un impulso notable a inicios de los 90 , cuando se establecieron dispositivos de política que promovieron la actividad empresarial privada en el campo, de cuyos resultados al año 2010 ya se había avanzado en una nueva concentración de tierras agrícolas, facilitando la apertura de empresas agrícolas y de agroindustrias de exportaciones no tradicionales. Los cultivos se vincularon más directamente al dinamismo, preferencias y fluctuaciones del mercado internacional, para cuyo propósito la diversidad geográfica del país ofrece ventajas comparativas. La agricultura experimentó así un nuevo cambio de cultivos, la exportación no tradicional, asentada particularmente en la costa, creció significativamente; al año 2000 ascendía a US \$ 394 millones y el año 2010 fue más de cinco veces mayor. Las exportaciones de espárragos, alcachofas, mangos, paltas y pimientos, figuran entre las principales. (BCR 2010).

La presencia de la mujer como asalariada ha agregado a su rol reproductivo en la familia un espacio en la producción, es decir, en la generación de ingresos. Los estimados hechos en base a la Encuesta Nacional de Hogares (ENAHO), permiten afirmar que entre los años 2003 y 2008 hubo un incremento significativo del número de asalariados rurales, que constituían 31.9\% del total de asalariados rurales del país, 
$33.1 \%$ entre los hombres y $29.1 \%$ entre las mujeres, siendo destacable el salto del empleo asalariado femenino rural en el sector primario, que se incrementó en $62 \%$ en el citado período. Una posible explicación es la feminización del trabajo asalariado en la moderna agricultura de exportación de la costa peruana (Eguren 2008).

Desde la década de los 80 se hizo cada vez más evidente la creciente incorporación de la mujer rural en actividades productivas agrícolas y no agrícolas. Si bien estuvo siempre activa, era básicamente cumpliendo la función reproductiva dentro del hogar. Las razones que impulsaron su participación como asalariada pueden resumirse en la caída del salario real del cónyuge, que hacía difícil seguir manteniendo las ya precarias condiciones de vida del hogar. La demanda de mano obra en la agroexportación apareció como una salida, asociada al crecimiento de una población femenina con relativo nivel de escolaridad, se presentaba como una alternativa que puso a la mujer en el mercado de trabajo.

En la actualidad se encuentran funcionando en Motupe cuatro empresas agroindustriales, las mismas que contratan aproximadamente a mil mujeres asalariadas que proceden de diferentes localidades, comunidades, caseríos y centros poblados circundantes al valle. Sin embargo aún no se conoce a profundidad las consecuencias que el trabajo asalariado agroindustrial ha provocado entre las trabajadoras involucradas. Nos interesa aquí explicar y descubrir tres aspectos del fenómeno, las condiciones regionales que permitieron la incorporación de la mujer como fuerza de trabajo en la agroindustria y el proceso de desagrarización del empleo femenino; cómo se insertan los cambios en la organización de los tiempos de trabajo asalariado y doméstico-familiar y otros por parte de la mujer, el impacto de la educación en dichos procesos y la experiencia del trabajo en la cosmovisión y conducta de las mujeres.

Los programas y proyectos de desarrollo agrícola impartidos por el Estado y organizaciones civiles, mas el impacto empresarial privado en la actividad agroindustrial, han suscitado cambios importantes en la estructura productiva de la región norte, que han tenido diversas repercusiones en la población de los valles de la región Lambayeque, entre ellas, la incorporación de la mujer rural al trabajo asalariado, junto a la introducción de productos comerciales, la mecanización y modernización de la agricultura; se originó una concentración de tierras. Los antiguos campesinos se vieron precisados a vender su fuerza de trabajo, así mismo, se incrementó el flujo migratorio de pobladores procedentes de comunidades y centros poblados rurales hacia centros urbanos, entre ellos Motupe, atraídos por la oferta de trabajo agroindustrial, trasladándose eventual o definitivamente a dichas ciudades.

La incorporación de las mujeres al trabajo requirió de una redefinición, tanto de las relaciones existentes en sus grupos sociales (unidades domésticas y comunidades), como de los acuerdos implícitos y explícitos con sus miembros familiares, en relación a las conductas que les eran permitidas. Así, las trabajadoras que en un inicio fueron vistas con recelo en su medio, utilizaron como mecanismo de protección y de ayuda las relaciones familiares.

La restructuración de la agricultura peruana tiene en la agroindustria de exportaciones de frutas y leguminosas a uno de sus pilares fundamentales, en correspondencia al papel activo de las transnacionales en el nuevo orden económico y «de las funciones actuales de la agricultura en la reproducción del capitalismo», etapa histórica que se conoce como "globalización», proceso que implica simultáneamente la concentración del poder del capital en la sociedad y una precarización de las relaciones laborales (Mejía 2002).

Es en este marco que las políticas liberalizadoras de las tres últimas décadas incentivaron la exportación de productos no tradicionales, como es el caso de las frutas y leguminosas, originando una creciente participación de la mujer en el trabajo agroindustrial, que no solo se caracteriza por la explotación extensiva del trabajo femenino, de largas jornadas, salarios bajos y condiciones adversas, sino fundamentalmente por una división sexual del trabajo. A la explotación del capital se suma la explotación de la sociedad, las mujeres están obligadas a combinar el trabajo asalariado con el trabajo reproductivo, se trata de dos tipos de trabajo diferentes pero ejercidos todos los días en forma desigual y simultánea, la doble jornada de trabajo que asume la mujer al incorporarse al trabajo asalariado.

El otro lado de la precariedad y flexibilidad del trabajo que impone la agroindustria a la población femenina es la individualización de las relaciones laborales. El origen de la desmovilización y desorgani- 
zación de las mujeres se encuentra en la inseguridad del trabajo asalariado, la inseguridad objetiva se traduce en inseguridad subjetiva (miedo a caer en el desempleo). Al respecto, Pierre Bourdieu (2000) propone el término "flexplotació0n» para definir la gestión racional de la situación de inseguridad en el trabajo que propician las empresas globalizadas, utilizando administrativamente el temor al despido para crear mayores condiciones de precariedad y explotación de los trabajadores.

La agroindustria en el país es promotora, por su naturaleza intensiva de mano de obra en todas las etapas de la cadena productiva, de aprovechar dicho dinamismo, capturando a la población pobre del país y en particular a las mujeres, mediante el mecanismo del empleo.

Hay que destacar que la canasta peruana de exportaciones agrícolas no tradicionales es muy variada, las legumbres y las frutas han llegado a ser los productos agroindustriales de mayor valor exportado. El año 2008 las exportaciones agrícolas alcanzaron 685 millones de dólares, lo que significó un crecimiento de casi 4 veces en relación al valor alcanzado en 1990 , esto se explica por los cambios no solo del mercado interno sino fundamentalmente a cambios en la demanda neta de los mercados de exportación.

Las referencias relativas a sus características operativas, tipifican a la agroindustria como una actividad intensiva en mano de obra, que conlleva a una expansión de la demanda laboral en las áreas de influencia locales. Yamada y Chacaltana (2007) estiman sobre la evolución del empleo en cultivos y actividades agroindustriales en las regiones del norte y plantean que en los años recientes el número de trabajadores agroindustriales ha ido en aumento y que además sus salarios se han incrementado de manera continua, tendencia que se mantendrá en tanto la actividad agroindustrial siga creciendo. Sin embargo, es necesario examinar las condiciones laborales e institucionales en torno a las cuales opera la mano de obra de la agroindustria peruana en estos años. Un primer aspecto tiene que ver con la temporalidad del empleo, quizá sea el punto más saltante que afecta las condiciones laborales y los ingresos

Examinando la relación entre empleo, género e ingreso se sabe que en el mercado de trabajo, las mujeres reciben remuneraciones menores, lo que lleva a percibir su rol como complementario en el ingre- so familiar, buena parte de esta diferencia de salarios es atribuida a una discriminación persistente en los mercados de trabajo de países en desarrollo, como sostienen Barclhan y Urdy. Los salarios tienden a incrementarse con un mayor nivel educativo, pero las mujeres trabajadoras enfrentan barreras legales y culturales para ingresar al mercado de trabajo.

Resultaría difícil analizar la relación de la mujer rural con el trabajo y las transformaciones que dicha relación está experimentando en los últimos años sin atender a procesos sociales más amplios, en los que podemos comenzar a encontrar las claves de interpretación de las nuevas estrategias ocupacionales femeninas, la disolución de las economías agrarias tradicionales, sancionada por la integración del mercado y la reformulación de la identidad social femenina.

La reconversión agraria ha tenido consecuencias diferentes en el orden laboral para hombres y mujeres, como muy diferentes son los supuestos de integración femenina y masculina en actividades no agrarias, a partir de la recomposición de los mercados de trabajo locales y de la importancia creciente de la multiocupacionalidad de las familias agrarias en el medio rural, la mujer rural ha perdido espacios tradicionales de laboriosidad femenina y se ha visto ante la participación desordenada de un mercado de trabajo que experimenta un paulatino proceso de desagrarizaciòn y que en la mayoría de los casos es todavía rígido como para resolver adecuadamente las demandas de empleo femenino no agrario.

La salarización y desagrarización constituyen las claves del cambio en las estrategias ocupacionales de la mujer rural. La recomposición de los mercados de trabajo locales, cuya lógica obedece en último término a una profunda cuasi desagrarización y desruralización, está amenazando incuestionablemente la organización económica social de los núcleos rurales.

La mujer joven constituye una reserva de mano de obra local, en razón a su edad y dado que las circunstancias familiares y culturales restringen su movilidad, favoreciendo eventualmente los fenómenos de salarización precaria en sectores manufactureros tradicionalmente femeninos, como en el caso de las agroindustrias de frutas y legumbres.

Atribuir las transformaciones del comportamiento laboral de la mujer rural únicamente a un proceso de creciente individualización y ruptura con la lógica familiar, de división del trabajo propia de la explotación 
familiar agraria, podría llevar a error, por cuanto que el grado de implicación de la mujer en actividades no agrarias y la forma que adopta dicha implicación debe analizarse también en el contexto de la pluriactividad de las familias rurales. Las características de la migración de la mujer en el mercado laboral no agrario nos remite también a ver el papel que juega la mujer en la multiocupacionalidad del grupo familiar.

Es preciso prestar atención a las condiciones en que se produce la creciente implicación de la mujer en actividades no agrarias, teniendo en cuenta tanto los factores etnoterritoriales y de configuración en los mercados de trabajo locales, como el papel que la mujer juega en la pluriactividad de las familias campesinas y las nuevas demandas que plantean las jóvenes generaciones de mujeres rurales. En este sentido se asiste a un trasvase de mano de obra femenina desde la actividad agraria familiar hacia el empleo agroindustrial, en actividades de tipo manufacturero feminizados. La emigración transitoria o permanente del ámbito local rural, en búsqueda de empleo, registra la huida de lo agrario y de lo local y la movilidad estacional implica para la mujer el abandono temporal de su inactividad o subempleo local por el empleo eventual como trabajadora asalariada.

La educación como trasmisora no solo de conocimientos de tipo instrumental, sino de un sistema de valores que conforman las expectativas individuales, constituye un elemento esencial del «rechazo" genérico a la actividad agraria y ello en un doble sentido: $1^{\circ}$ el incremento del nivel educativo de las jóvenes respecto a sus padres y en $2^{\circ}$ lugar la tendencia hacia una prolongación de los estudios por parte de las chicas frente a los chicos, constituye no solo el reflejo de la más dificultosa inserción de la mujer en los mercados de trabajo locales, sino también la expresión del deseo de escapar al destino de sus madres.

La problemática de inspiración feminista de la doble jornada de las mujeres trabajadoras y de la conciliación entre la vida profesional y familiar, que junto al tema de la jornada interminable, es un problema actual que se expresa paulatinamente en el mundo del trabajo femenino. Se torna más problemática la situación de la doble jornada en el caso de las trabajadoras asalariadas rurales que también realizan labores agrícolas en el predio familiar.
Se propone analizar los profundos cambios que se vienen produciendo en la configuración del tiempo de trabajo en la sociedad peruana actual y cómo dichos cambios impactan en los tiempos de vida de los trabajadores y muy en particular sobre la vida doméstica familiar. En la presente investigación se explicará la problemática relacionada con una nueva configuración del tiempo de trabajo de los trabajadores asalariados de la agroindustria, la forma cómo el cambio en el orden temporal del empleo hunde sus raíces en transformaciones económicas y sociales de gran calado (desagrarización del empleo) y las implicancias del tiempo de trabajo desde el punto de vista empresarial en el uso de la fuerza de trabajo femenina y sus costos sociales.

En lo referente a los tiempos de trabajo, es importante iniciar el análisis de los sujetos y sus actividades y luego hacer lo propio con los tiempos de trabajo de las mujeres asalariadas. Desde esta perspectiva es central conocer la cuestión de los tiempos de trabajo asalariado y de cuidados doméstico familiares, cuya distribución tiene su origen en las relaciones de género.

Hacer posible la configuración de las dos actividades citadas es complejo, aun a costa de reducir su complejidad hay que reconocer al menos cuatro grandes dimensiones que tienen que ver con «cuanto, cuando, como y quien del trabajo». Cada una de las instituciones en que se insertan dichas dimensiones tiende a fijar su propio contenido en aquellas dimensiones de sus tiempos, siguiendo una lógica que es propia en cada caso (Ramos 1999). Dimensiones de tiempos de trabajo en las que se hace más evidente la profunda transformación que vienen sufriendo en las últimas décadas.

Los cambios en el orden temporal del trabajo, actualmente más visibles y efectivos, afectan las cuatro dimensiones del tiempo del trabajo. Esos cambios se concentran en fenómenos tan notorios como la diversificación de la duración y horarios de trabajo, la flexibilización en sus múltiples modalidades, la difuminación de fronteras entre el tiempo de trabajo y los otros tiempos y la creciente desincronización de los tiempos de sociales. ${ }^{1}$ Estos cambios han adquirido

1 Se entiende por "Tiempos sociales» aquellos que comprenden las relaciones de trabajo con el resto de tiempos sociales, entre los que destaca el tiempo social dedicado a las actividades doméstico-familiares. Havil 1993 y Hiquielles 2004. 
un significado especial por el hecho de haberse visto acompañados por una importante modificación de las pautas de actividad de las mujeres.

A manera de hipótesis se plantea: La actual percepción y apreciación de la configuración del tiempo de trabajo se caracteriza por una serie de rasgos comunes: a) los profundos cambios que se observan actualmente en el orden de la temporalidad social del trabajo profesional y de los cambios familiares, generan la sensación de que se esta viviendo un momento traumático, caracterizado por la escasez relativa de tiempo. b) En la medida de que el tiempo de trabajo es un tiempo que ha sufrido en las últimas décadas profundas transformaciones que, por un lado, escapan del control de quienes trabajan y que es una causa del desorden y tensión general y c) La particular posición y relación de la mujer con el mundo laboral y el doméstico, lleva a señalar que existe un fuerte control entre su percepción y apreciación de un tiempo problematizado en relación al de los hombres.

La actividad de las mujeres, particularmente casadas, antes de la etapa de diversificación productiva iniciada por los años 80 en los valles de Lambayeque, se limitaba a una dedicación casi exclusiva a los cuidados domésticos, mientras que en el presente es mas bien normal, que la mujer sea económicamente "activa», sin que ello sea óbice para mantener su dedicación a las tareas domésticas. El cambio en este ámbito, como se pretende demostrar con la información empírica es muy importante, por ser la base de la cuestión "conciliación entre la vida profesional y doméstica» (Prieto, Ramos y Gallego 2008).

En el estudio se trata de explicar las interrelaciones entre la esfera de la producción mercantil y la esfera familiar doméstica, analizando las conexiones e interdependencias entre la organización del trabajo del mercado y la actividad de cuidados, en lo que al uso y distribución de los tiempos se refiere. Lo anterior se traduce en conocer, desde una perspectiva de género, dos procesos muy relacionados: La transformación en la organización del tiempo de trabajo en la producción mercantil, en la cual se da la flexibilidad horaria de jornadas y los cambios en la participación laboral de los trabajadores, que según Carrasco y otros (2003), estarían empleando nuevas organizaciones de los tiempos por parte de los miembros de la familia, particularmente de las mujeres asalariadas.
Se trata de dos clases de actividad, las propias del trabajo asalariado en la empresa y a su lado, o entremezcladas, las actividades del cuidado y la atención doméstico familiar. Dos instituciones sociales, la empresa, o mejor el trabajo asalariado, en cuyo seno las trabajadoras realizan las actividades de trabajo y la unidad de convivencia doméstica. Siendo así las cosas, la configuración del tiempo de trabajo y su articulación con el de la actividad doméstica se verá atravesada por la forma cómo opera cada institución implicada, cómo se definen y se relacionan mujeres y hombres dentro de ese espacio y cuál es la relación entre uno y otro.

El estudio de los tiempos sociales y de su entramado adquiere un relevancia especial en momentos en que las sociedades viven grandes cambios en la organización de sus actividades y en la diferenciación de sujetos, con la información empírica que recopilamos, buscamos explicar cuáles son las tendencias de cambios que vienen afectando el tiempo de trabajo, porque la fuerte alteración que viene sufriendo la configuración social del tiempo de trabajo en la actualidad, tal como se da en el proceso de desagrarización del empleo, que según Thomas (2000), se halla relacionada sobre todo con las transformaciones del tiempo de trabajo y cuya organización social viene sufriendo cambios profundos en las últimas décadas, en todos los países, el cambio es tan visible, que avanzamos "hacia el fin del trabajo", entendiendo por tal fin al modo en que el tiempo de trabajo se hallaba organizado y regulado. El cambio consiste ante todo, en la sustitución de una pauta general según la cual tendían a homogenizarse, estabilizarse todas las dimensiones del tiempo de trabajo y otra en la que tiende a implantarse la heterogeneidad, la diversidad, la variación.

\section{Desagrarización del empleo femenino}

En los ańos 80 se inicia en los valles del departamento de Lambayeque la instalación de las primeras industrias procesadoras de frutos y de legumbres, cuyos productos destinan principalmente a la exportación, recurriendo para el efecto a la contratación de mano de obra femenina de la región. Las asalariadas rurales de las agroindustrias de Motupe son en su mayoría contratadas eventuales, trabajan entre 120 y 180 días 
al año, en períodos irregulares según las necesidades temporales del empleador, cumpliendo jornadas de trabajo de ocho diarias y eventualmente mayores. Si bien, el trabajo asalariado se ha extendido a lo largo y ancho del país, especialmente en la costa y sierra, las condiciones de trabajo marcan lo que se ha dado en llamar la precarización del trabajo, significativo en el caso de las mujeres rurales. Si bien es cierto que la agroexportación incorpora a la mujer a la actividad productiva, lo hace en condiciones muy precarias por el lado que se quiera ver: bajos salarios, jornadas laborales extensas, trabajo temporal, entre otros.

La población económicamente activa (PEA) de 6 y más años de edad del departamento de Lambayeque era de 400,505 personas el año 2007, habiéndose incrementado $44.6 \%$ en el periodo intercensal 1993 2007. Estaba compuesta por una amplia mayoría de hombres $(67.7 \%)$, mientras que la PEA de mujeres era muy reducida $(32.2 \%)$, no obstante que el crecimiento de la PEA de mujeres en el citado periodo superó en números absolutos al crecimiento de la PEA de hombres. Fenómeno que denotaría una inflexión significativa hacia el crecimiento de la PEA femenina en dicho departamento. La proporción de PEA ocupada de hombres y mujeres era aproximadamente equivalente, algo mayor al 94\%, en ambos casos.

El distrito de Motupe tenía el ańo 2007 una PEA total de 8,105 personas, equivalente al $2 \%$ de la PEA departamental de Lambayeque, sin embargo, sus características de distribución y crecimiento guardan correspondencia con las del departamento. Creció cerca del 33\% entre los ańos 1983 y 2007. La PEA femenina distrital en 2007 era solo una cuarta parte del total, pero ya se advirtió entonces su mayor tasa de crecimiento, superior a la masculina.

La mujer joven tiende a desvincularse de lo familiar-agrario, favorecida por el respaldo económico familiar y en sintonía con las oportunidades de salarización que ofrece el desarrollo del empleo agroindustrial no especializado, socialmente más valorado. Una mayoría relativa de las mujeres asalariadas refieren ser solteras $(41.2 \%)$, siguiéndoles en orden descendente las convivientes $(38.2 \%)$, las casadas $(17.6 \%)$ y las viudas, en una proporción inferior (2.9\%). La edad promedio de las mujeres encuestadas es de 35 años; por grupos de edad, se aprecia que es mayoritario el grupo de adultas de 26 a 45 ańos (52.9\%), seguido de las jóvenes de 18 a 25 años (23.5\%) y finalmente las adultas mayores, de 46 a 64 años (20.6\%).

En las relaciones que se establecen entre las trabajadoras, pesa su origen geográfico y social. Esto se refleja en su distribución en las áreas de trabajo, ya que generalmente se agrupan en las mesas de trabajo según el lugar de su procedencia, asimismo, son notables los gestos de solidaridad en razón a sus relaciones familiares. Las mujeres encuestadas, viven en centros poblados rurales del valle de Motupe, tales como el Arrozal, Molino, Palo Blanco y Las Pampas, excepto una minoría de seis por ciento que viven en la ciudad de Motupe.

Si algo caracterizaba hasta hace recientes ańos la estructura social del mundo rural era la omnipotencia de la familia como unidad de producción y consumo, convivencia mutua, ayuda y socialización, que explicaba su capacidad de resistencia y de sobrevivencia económica ante el empuje de las fuerzas macroeconómicas del capitalismo. Sigue siendo difícil romper con la imagen de mas mujeres rurales integradas en un mundo de lealtades familiares y comunitarias, en los que el conflicto de género no tiene razón de ser y quizá donde mejor se refleja este prejuicio es en el análisis de la actividad laboral de las mujeres rurales: nadie pone en duda que para la mujer, acceder al mundo laboral es un factor estratégico de emancipación social, aparte que es una manera de subsistir o cubrir una serie de necesidades materiales (Whatmore 2013).

La progresiva conversión de la agricultura en una actividad empresarial tiene como resultado el replanteamiento de las relaciones entre los trabajadores que integran la explotación familiar que tiende a definirse desde bases de tipo mercantil, sin embargo respetan la tradicional división del trabajo patriarcal. La integración cada vez mayor de la agricultura familiar en el mercado es el proceso que provoca y rompe la lógica interna propia de la agricultura tradicional, la distorsión del papel social y laboral de la mujer, categorizado como "reproductivo» en oposición al ámbito "productivo", central de una actividad cada vez más sometida a la lógica del mercado.

La antigüedad promedio de las mujeres encuestadas en los mismos centros agroindustriales de su trabajo actual es de 6.7 años. Las tareas que desempeñan la mayor parte de dichas obreras son las operaciones de pelado, cortado y traslado y/o alimentación del 
material en proceso a los sistemas de congelado, le siguen en orden decreciente aquellas que se dedican a la selección de frutas y de hortalizas y finalmente las operarias de empaquetado y embazado.

La ocupación anterior a su desempeño como asalariadas en la agroindustria, por parte de las mujeres encuestadas era, en una proporción cercana al $50 \%$ de casos, la de amas de casa en sus hogares, grupo al cual se agrega $21 \%$ de mujeres que, adicionalmente a ser amas de casa, realizaban laboreo de sus tierras, grupos menores, equivalentes cada uno a $6.5 \%$ de encuestadas habían realizado trabajos agrícolas, otro grupo habían estudiado paralelamente al trabajo agrícola, otras que solo habían estudiado y finalmente un cuarto grupo que tenían pequeños negocios comerciales.

Según la encuesta, el 100\% de los empleos son eventuales, se contratan en las empresas unas siete veces al año, seis o más días por mes, la mayoría de las empleadas ingresan al trabajo a las $7 \mathrm{a} . \mathrm{m}$. y salen a las $5 \mathrm{pm}$. Casi la totalidad de mujeres tienen contrato eventual, incluye un seguro de salud. Solo un margen pequeño de tres por ciento de trabajadoras se encuentra en planillas y tienen beneficios sociales, incluido el seguro de salud. La eventualidad y flexibilidad del trabajo es notoria en la agroindustria de Motupe, la misma que se agencia de mano de obra femenina y rural, no calificada,

Consideramos central el papel que, en la organización del tiempo de trabajo juega la relación entre el trabajo asalariado y los cuidados domésticos - familiares y el de las relaciones de género, incorporando la relación entre empresa y unidad de convivencia; para visualizar el modelo de trabajo - tiempo que se aproxima a las empresas agroindustriales de Motupe, Lambayeque, caracterizadas por su flexibilidad ocupacional, alta inestabilidad por su notable temporalidad en los contratos de trabajo, atipicidad en la duración de las jornadas (tiempo parcial, con variable números de horas). Al respecto, el estudio permite distinguir los siguientes rasgos:

- Bajos salarios

- Baja cualificación

- Variable organización de tiempos de trabajo, decidida por la empresa.

- Inestabilidad laboral, involuntaria en el caso de las mujeres casadas y voluntaria, en el caso de las trabajadoras jóvenes.
- La participación, tanto de trabajadoras jóvenes que aún residen en la casa paterna, y de mujeres casadas, que consideran su trabajo como un medio para complementar el salario de sus maridos y que disponen de una red familiar mínima para atender los cuidados familiares.

En lo referente a la disposición personal para continuar en el mismo centro de trabajo, las respuestas están divididas, un $56.7 \%$ responde que piensan continuar en la misma empresa y otro grupo de $43.3 \%$ que señalan que les gustaría cambiar de trabajo. Las explicaciones de las mujeres trabajadoras sobre su disposición para permanecer o cambiar de empleador muestra el siguiente panorama:

Entre los motivos para continuar laborando en la misma empresa se distingue: un $26.7 \%$ señala que ya dispone de empleo y no desea aventurarse en búsqueda de otro trabajo, otro $20.0 \%$ afirma que ya se adaptó al empleo actual y que le costaría adecuarse a un nuevo empleo, otros cinco grupos menores refieren diversas motivaciones.

Quienes desean cambiar de trabajo justifican su posición en dos aspectos; $43 \%$ afirman que los ingresos que actualmente perciben son pequeños y un $23 \%$ de ellos quieren mejorar su situación económica.

El $88.2 \%$ de las mujeres trabajadoras cobran semanalmente sus salarios y $11.8 \%$ lo hacen cada quincena. El ingreso promedio por el trabajo asalariado que realizan es de S/ 277.97 por semana. Los ingresos más frecuentes son de S/ 300 a S/ 310 y los menos frecuentes son de $S / 270$ a S/ 200.00 semanales.

Una mayoría de $55.9 \%$ de las mujeres trabajadoras encuestadas dedican sus ingresos a necesidades personales así como también a complementar sus ingresos familiares, otro $35.3 \%$ de las mismas los dedica a complementar sus ingreso personales, principalmente. Para dichas mujeres es muy significativo trabajar por un salario, cerca del $53 \%$ señala que es importante y $47 \%$ enfatiza que es muy importante, justificando fundamentalmente por ser un aporte económico necesario para sus necesidades familiares y personales.

El análisis de las respuestas relativas a la satisfacción o conformidad con el trabajo en la agroindustria nos muestra que aquellas que señalaron estar satisfechas, lo explican mayoritariamente por ser un ingreso propio 
para afrontar sus necesidades, en menor proporción refieren sentirse capaces de ayudar económicamente a su familia. Entre las que respondieron sentirse indiferentes, el $66.7 \%$ buscan otro trabajo y $33.3 \%$ de las mismas explica que le gustaría ganar más dinero. La totalidad de las trabajadoras de la agroindustria encuestadas justifican su dedicación a dicha labor en razón a motivos económicos.

Sobre experiencias de trabajo asalariado anteriores al actual, la totalidad de las mujeres refirieron no haber realizado trabajo asalariado alguno. Un 51.2\% de ellas se habían dedicado únicamente al cuidado del hogar, $21.2 \%$ a estudiar y $15.2 \%$ al hogar y trabajo en el campo, El significado del trabajo asalariado que actualmente realizan las mujeres, distingue una mayoría de $61.8 \%$ para quienes es importante, porque se complementa con sus otras actividades, un $20.6 \%$ de mujeres señalan que significa una independización de sus actividades no remuneradas y un tercer grupo de $17,6 \%$ para quienes ambas razones son importantes. Por otro lado, $94.1 \%$ de mujeres señalan que su trabajo les ofrece mayor independencia económica y social, contrariamente, una minoría de $5.9 \%$ de las mismas lo niegan.

La situación descrita es respaldada generalmente por la familia de cada trabajadora. En efecto, un $82.4 \%$ de las encuestadas señalan que su familia o pareja las apoyan por su actividad, $14.7 \%$ dice que la familia es indiferente, sin embargo, $2.9 \%$ de mujeres refieren que su familia o pareja están en desacuerdo con su trabajo.

Entre las mujeres cuya familia o parejas están de acuerdo con su trabajo, $47.8 \%$ señalan que su salario es una ayuda para la familia, el $34.8 \%$ porque obtienen más ingresos familiares y $13.0 \%$ porque le permite mayor independencia económica la mujer. De los que están en desacuerdo, el $100.0 \%$ refieren que dejan solos a los hijos, ocasionando malestar en el hogar. Las explicaciones de los familiares indiferentes aluden a que el pago no es justo y que dejan solos a los hijos, cada uno con $40.0 \%$; un tercer subgrupo de $20 \%$ de estos últimos, prefieren que la mujer busque otro trabajo más rentable.

La percepción del impacto que generan las empresas agroindustriales instaladas en la zona sobre la vida y bienestar de los pobladores es definidamente positiva, según lo afirman $90.9 \%$ de las encuestadas; un margen minoritario de $9.1 \%$ afirman que influyen negativamente. La explicación del $66.7 \%$ de las mujeres que señalaron que dichas empresas influyen positivamente en la vida y bienestar de los pobladores especifica que el mayor impacto se aprecia en mayores posibilidades de trabajo para la población, seguido de un grupo de $18.5 \%$ de mujeres que señalan que hay una mejora en la calidad de vida y un tercer grupo minoritario de $7.4 \%$ de mujeres que afirman que hay una mejora económica. En el sector minoritario que señalaron que las citadas empresas influyen negativamente, dos terceras partes sostienen que estas empresas generan problemas, sin embargo en este mismo sector minoritario un tercio de las mismas reconoce que hay una mejora económica en la zona.

La totalidad de mujeres seńala que la operación de estas empresas agroindustriales y de otras en la zona ha generado cambios visibles en el desarrollo y bienestar de la población. Un 37.9\% señala que el cambio más notable en la ciudad es la generación de un mayor numero y diversidad de negocios y servicios; dos grupos, cada uno de $17.2 \%$, afirman haber mejor organización y seguridad contra la delincuencia y una mayor urbanización. Con respecto a la percepción sobre cambios operados en el campo, $41.4 \%$ señala que ha mejorado la producción, el $37.9 \%$ refiere que el campo se ha despoblado y $17.2 \%$ que se ha «urbanizado» el campo, en el sentido que hay más servicios .

La quiebra de las relaciones patronales tradicionales en la sociedad rural constituye la crisis del papel de la mujer en la agricultura familiar, en razón a la incorporación de ésta en actividades no agrarias y más concretamente, al mercado de trabajo. La situación es la de un mundo rural que se enfrenta a una crisis de reproducción rural. Por un lado, la salarización de los cónyuges de las agricultoras y por otro lado, la huida de las mujeres jóvenes, el rechazo al matrimonio con agricultores y con el trabajo agrario y el medio rural, también ellas expresan sus reivindicaciones, un estatuto igualitario, una reformulación de la identidad profesional acorde a la modernización del sector.

Es el sistema de relaciones en el que las personas realizan su trabajo y no el tipo de trabajo en si mismo el que determina el status y nivel de autonomía real. De lo que se deduce que la desagrarizaciòn del trabajo de la mujer no tiene necesariamente porque implicar una variación sustancial de la condición social de la mujer. Aunque sí es perceptible para la mujer que 
la diversificación de actividades y concretamente el trabajo asalariado ejercen una positiva incidencia en su independencia económica, autoestima y su valoración social.

El proceso de trabajo dentro de la explotación familiar comprende varios ámbitos laborales donde se inserta el trabajo remunerado fuera de la explotación familiar, que implica una separación física y/o espacial de las actividades, pero aun estos circuitos laborales están interrelacionados en la práctica, formando parte de la lógica y estrategia familiar. En realidad el trabajo de la mujer fuera de la explotación familiar no significa que no participe laboralmente en la misma y especialmente no excluye echar una mano en los momentos de más trabajo, ni que se destinen más ingresos a las necesidades personales o de la familia exclusivamente. De esta forma los tradicionales beneficios que reporta la mujer en el campo se están modificando, se hace cargo fundamentalmente del trabajo doméstico y eventualmente de parte del trabajo en la producción, beneficios que hasta pueden ser incrementados, con la ventaja que representa la apropiación del salario de la mujer y de su capital cultural en términos de su acceso a un determinado estilo de vida y de socialización en la cultura nueva urbana y moderna (Berlan 1988).

Sin embargo la desagrarización del empleo femenino de las familias agrarias aun no es algo distinto a la transfiguración de la "ayuda familiar», no es posible aun imaginar familias con más relaciones de género sustancialmente «diferentes» $y$ aun se impone el prejuicio de considerar el comportamiento laboral de la mujer como funcional, en último término, para la explotación agraria familiar. Se plantea, en general, que la transformación de las pautas laborales femeninas en el medio rural y en concreto la desagrarizaciòn del empleo de la mujer rural, expresa la disolución de la economía campesina tradicional y la reincorporación de la agricultura familiar al sistema de mercado capitalista.

Si el movimiento de emancipación familiar en el contexto urbano industrial podría identificarse como un movimiento que lleva a la mujer desde la esfera de la reproducción a la esfera de la producción, en el medio rural se trata en primer lugar de que la mujer se encuentra en una situación clara de reproducción (ama de casa) o de producción, como trabajadora. Existe por lo tanto un doble movimiento desde la condición de "ayuda familiar» agraria al de ama de casa y desde la misma condición al de trabajadora, lo que interesa al estudiar la transformación de las pautas laborales femeninas en el medio rural no es tanto el aumento o la disminución de la actividad como el aumento de trabajadora remunerada «de trabajadora de verdad».

La desagrarización del empleo, en la medida que implica una desvinculación de las formas familiares de producción, representa mediante el salario la objetivación del trabajo y la directa participación en el mercado, expresa la mejora del estatus laboral femenino en términos de remuneración, autonomía y reconocimiento, es decir el trabajo asalariado de la mujer rural y los nuevos elementos introducen las características de la desagrarizacion y el proceso de cambio en las pautas laborales femeninas. De lo que se desprende la idea de la naturaleza flexible y acomodaticia del trabajo femenino en las comunidades rurales. Toda nueva experiencia laboral de la mujer tiende a ser vista bien como sustitutiva, bien como resultado de la adopción de nuevas necesidades del aparato productivo o de las influencias externas de la cultura y sociedad urbana.

La incorporación de las mujeres campesinas a actividades no agrícolas constituye una opción interesante para las mujeres de familias rurales menos favorecidas. La permanencia de la pequeña propiedad agropecuaria entre las familias de las trabajadoras queda de manifiesto según los resultados de la encuesta realizada. Hemos encontrado que dos terceras partes de las mujeres encuestadas indicaron que poseen tierras de cultivo, las mismas que las cultivan a nivel familiar. Una mayoría absoluta de $95.7 \%$ de encuestadas con tierras de cultivo refieren que las mismas son de su propiedad y el restante $4.3 \%$ indican que las tierras que cultivan son alquiladas. El tamaño promedio de dichas tierras (propias y alquiladas) es de $0.8 \mathrm{~h}$. Los principales cultivos son de maíz, frutas y arroz.

En lo referente al manejo pecuario practicado por las familias poseedoras de pequeńas tierras agrícolas, solo una minoría de las mismas $(41.2 \%)$ crían animales, generalmente menores. Las crianzas más frecuentes son de aves de corral, les siguen las de ovejas y cabras y en menor proporción de vacunos.

La participación de las mujeres asalariadas de la agroindustria en labores agrícolas de los predios familiares todavía es significativa, un $38.2 \%$ de ellas lo reali- 
za, prolongando así su actividad laboral, trabajan en el campo los días de descanso del trabajo asalariado. Una mayoría de $61.8 \%$ de encuestadas con predio agrícola no participan en trabajos agrícolas. Por otro lado, se ha determinado que una mayoría de dos tercios de mujeres labora en actividades productivas no agrícolas los días feriados y domingos y el tercio restante de mujeres encuestadas realiza dichas labores los sábados.

Los resultados expuestos, indicativos de que si bien todas las trabajadoras asalariadas son residentes de zonas rurales, subsiste un sector minoritario de las mismas que realizan actividades agrícolas como ocupación secundaria; en el valle de Motupe se viene dando un proceso de industrialización y una relativa dotación de servicios. Se han invertido las oportunidades y objetivos del empleo femenino: las mujeres de las clases económicas menos privilegiadas se están incorporado a las actividades secundarias y de servicios.

La presencia femenina en actividades productivas asume una función sustitutiva al remplazar la mujer al hombre en tareas que el desarrollo económico le permite desdeñar o bien una función integrativa, cuando la mujer ejerce actividades que considera propias de su sexo, tal es el caso de las trabajadoras agroindustriales, dedicadas a actividades relativas al manejo de productos agrícolas (selección, clasificación, envasado, congelado de frutos y legumbres) que implican habilidades y destrezas propias de las mujeres; «sin embargo, falta aún la función competitiva, cuando emprenda una lucha por la igualdad de su acceso al empleo y a todos los aspectos de la vida social y política» García Fernando (1977). Según esta visión, la incorporación de la mujer al mundo laboral no agrario, aparece aún con un carácter marginal y subsidiario, como una opción involuntaria de mujeres que pertenecen a grupos menos pudientes.

Hay que señalar la influencia que puede tener en la evolución de la población activa agraria las transformaciones en el comportamiento de la familia como son: los cambios intergeneracionales e interconyugales de las familias agrarias y en concreto la crisis del status de «ayuda familiar» (García Fernando), particularmente visible en el caso de las hijas de agricultores, que las impulsa a la búsqueda de empleos ajenos al sector. En este sentido se puede plantear que es innegable el reconocimiento de factores de tipo social que suponen una quiebra significativa del comportamiento ocupacional de la mujer.
Desagrarización y salarización son en efecto las dos palabras claves que expresan la fisura generacional en el orden laboral de las mujeres rurales. El salario aparece como máximo signo de independencia económica familiar y como elemento central de autonomía e individualización económica familiar del mundo rural. El proceso de desagrarización del empleo femenino en el medio rural del Perú permanece todavía escasamente investigado, sin definir las repercusiones que en cada contexto territorial está teniendo la desagrarización en la condición socio-laboral de la mujer.

Se asiste a la descomposición de un modelo tradicional de laboriosidad femenina y a la emergencia de nuevas pautas ocupacionales que a la vez expresan las profundas mutaciones económicas y sociales del mundo rural, nos muestra una clara fisura generacional, tanto por lo que se refiere a pautas de actividad como a valores, actitudes y expectativas vitales. La extensión de la pluriactividad de las familias rurales en las sociedades industriales puede constituir un interesante marco de referencia para analizar el proceso de desagrarización del empleo femenino en el medio rural.

En las últimas décadas se asiste en efecto en el Perú a un profundo cuestionamiento de los supuestos centrales de la especificidad de los sistemas sociales rurales que se consideraban caracterizados por la solidaridad interna, la importancia de los lazos de parentesco, el apego a las tradiciones y la resistencia al cambio, se observa al presente una materialización del fin de la comunidad. La integración mercantil de la agricultura, el crecimiento del empleo secundario y terciario en los espacios rurales, una creciente movilidad poblacional entre áreas rurales y urbanas, el uso creciente de espacios rurales como lugares de ocio, esparcimiento o residencia, la innegable extensión de "formas de vida urbanas» más allá de las ciudades deja sin sentido la tradicional dicotomía entre el mundo rural y el mundo urbano.

Uno de los rasgos más característicos de la ruralidad de las sociedades modernas industriales es la pérdida de importancia de la actividad agraria como fuente de empleo, la dimensión territorial de la desagrarizaciòn, el éxodo rural, concentración urbana y la distancia e interacción con otros medios de mayor envergadura. Asimismo los cambios en las pautas de actividades y empleo de las mujeres rurales, el hecho de que la disminución de la población activa sea 
considerablemente mayor que la disminución de la población rural total (PEA) es un indicador de los asentamientos rurales.

La desagrarizaciòn de la población rural ha estado asociada a un declive demográfico y social al no surgir nuevas actividades económicas que restituyan la agrícola tradicional. Así, en la zona de estudio, la agricultura ha ido descendiendo al mismo tiempo que el despoblamiento y envejecimiento de la población inciden en el mismo sentido, la población activa crece como resultado básicamente de la integración femenina en el mundo laboral. Adicionalmente, la actividad juvenil es la que más claramente refleja las oportunidades para la integración de la mujer en el mundo laboral. El estado civil es un factor tan básico como la edad en el comportamiento de la actividad económica. El matrimonio comienza a perder importancia como factor condicionante de la mujer respecto a las actividades frente a estrategias generacionales vinculadas a nuevos valores, actitudes y expectativas, respecto a la propia vida social y laboral.

Las oportunidades de empleo no agrario para el acceso de la mujer al mundo del trabajo, dependen de la accesibilidad y cercanía a los centros de mayor dinamismo económico y demográfico, como se da en el caso de las empresas agroindustriales en la zona de Motupe, en cabeceras comerciales, muy próximas a las zonas rurales. Las mujeres dedicadas a actividades rurales y que tienen cierta familiarización en el manejo de productos agroalimentarios ven facilitadas sus opciones de acceder a los empleos agroindustriales.

Es posible señalar los siguientes rasgos generales del proceso de incorporación laboral asalariada de la mujer rural de Motupe a la actividad agroindustrial:

La desagrarizaciòn de las mujeres activas menores a 40 años es sin duda el rasgo básico de la evolución sectorial del empleo femenino. La integración salarial no agraria de la mujer es más intensiva entre las generaciones jóvenes.

La desvinculación de las mujeres jóvenes de la zona rural respecto a la agricultura hace que estas presenten no solo un perfil de empleo radicalmente distinto al de sus congéneres adultos sino muy diferentes al de sus coetáneos varones.

Por otro lado, las características del desenvolvimiento del mercado de trabajo agroindustrial en Motupe inducen a plantear que la propia estructura social y económica del medio rural y, sobre todo, que una parte considerable de la economía y el empleo rural, ajena a los parámetros propios de la organización capitalista del trabajo y producción, favorece a la proliferación de pautas laborales atípicas como son la desrregulaciòn, flexibilización y en general la informalidad del mercado de trabajo.

El empleo no agrario es función de la insuficiencia o suficiencia de la explotación agraria. La desagrarizaciòn laboral de la mujer se asocia más directamente con la pequeña agricultura, mientras que no experimenta variaciones entre las explotaciones medianas y grandes.

No hay que descartar en el caso de las mujeres y los jóvenes la posibilidad de que más allá de la importancia objetiva, en tiempo dedicado y remuneración obtenida, siempre se considera principal aquella actividad que aparece objetivada por el mercado y por el salario.

Por lo que respecta al trabajo no agrario, puede que no existan diferencias significativas entre las mujeres rurales de diferentes regiones, pero es evidente la diferencia abismal que separa la agricultura del trabajo no agrario, tanto en lo relativo a estabilidad, reconocimiento y remuneración, como en valoración social.

El tipo de factores culturales asociados al contenido y estatus de cada ocupación es un elemento esencial a la hora de analizar y entender el proceso de desagrarización del empleo femenino rural. Uno de los rasgos más relevantes del universo valorativo femenino en relación al empleo, es la consideración de la estabilidad como característica más apreciada, incluso más que el dinero reportado en su trabajo. La estabilidad parece ser la condición "sine qua non» de mejores condiciones trabajo y de oportunidades de cualificación, mayor reconocimiento social y legal y, en definitiva, de una profesionalización.

Otro rasgo esencial es el fuerte rechazo de la condición de ayuda familiar, de tal forma que, con la misma intensidad con que la mujer se desarraiga de la agricultura, se plantea una clara huida de las relaciones productivas familiares. Este tipo de relaciones productivas en el medio rural, lleva a plantear, como un elemento estratégico de emancipación femenina del arraigo rural hacia la transformación de las condiciones en que se ejerce el trabajo de la mujer en el seno de las empresas. 
Entre las trabajadoras agroindustriales, un sector minoritario proceden de familias rurales no campesinas (familias sin tierras), las mismas que viven esencialmente del trabajo asalariado, que consiguen sea localmente o también vía migraciones temporales. Los arquetipos de la vida rural se ven sustituidos por la migración y el trabajo asalariado precario. Parece entonces justificado hablar de un tránsito de un mundo campesino agrario, dominado por la producción agropecuaria familiar a un mundo rural en donde predomina el trabajo asalariado y la familia no campesina. La persistencia de los hogares campesinos y no campesinos no corresponde solamente a la fuerza de los vínculos comunitarios, tal como se planteaba hace algunas décadas, sino principalmente a la actual situación del trabajo escaso y precario, incapaz de absorber la mano de obra sobrante del campo. En algunos casos que se dan en Motupe, el incremento de las actividades asalariadas de miembros de las familias no provoca la desaparición de la unidad de producción, sino la transformación de su lógica organizativa, sin dejar su vínculo con la tierra, estas familias aprecian de igual forma sus actividades no agrícolas.

Un aspecto en la transformación de la sociedad rural es el crecimiento de hogares que no trabajan en la agricultura, ni como productores ni como asalariados, pero que permanecen en su localidad de origen, mientras sus miembros buscan ubicarse en el mercado de trabajo, como en el caso del estudio, o vía procesos migratorios cada vez más complejos, situación que provoca la dasagrarización del campo, entendida como la disminución del empleo y del ingreso agrícola total.

En la actual unidad económica campesina se mantendrá la agricultura, como actividad económica más rentable, si ésta genera los mayores ingresos económicos para la unidad de producción, pero será el trabajo asalariado el que cobre mayor importancia, cuando el mercado de trabajo ofrezca mayores posibilidades de ingresos que el mercado de productos agropecuarios. Parece que esta segunda posibilidad marca definidamente la tendencia actual. En el Perú la misma noción de retorno se vuelve ambigua. Qué sustento tiene el retorno a casa o cuáles son las alternativas que ofrece, cuando ya no hay trabajo suficiente, cuando la separación entre el lugar de residencia y el lugar de trabajo se torna en característica estructural de la precarización del mercado de trabajo.
Es importante plantear el papel que en la actualidad juegan los medios de comunicación, facilitando información económica y social, al alcance los pobladores rurales. Referimos así que una gran mayoría de las mujeres asalariadas en la agroindustria de Motupe se informaron de la oferta de trabajo mediante las radios locales. Asimismo, es relevante anotar el mejoramiento de las vías y servicios de transporte, facilitando la movilización de las poblaciones.

La educación es reconocida como la vía para el logro de mejores niveles de inserción en los mercados de trabajo, mejorando la productividad e incrementando los ingresos. La escuela es capaz de ofrecer a las jóvenes trabajadoras rurales otras visiones del mundo y perspectivas, capacitando en ellas una nueva identidad para asumir nuevos roles, determinantes en el desarrollo de su autoestima. Por otro lado, los mercados de trabajo en la medida que son superiores, demandan niveles crecientes de escolaridad y capacitación, para afrontar la competitividad.

El nivel educativo de las mujeres es predominantemente bajo, $64.5 \%$ de ellas solo ha alcanzado educación primaria, $29.0 \%$ estudios secundarios y apenas $6.5 \%$ estudios técnicos superiores. Las trabajadoras agroindustriales del valle de Motupe, muestran en general un perfil de mujeres rurales, predominantemente con un escaso nivel educativo. Su formación limitada a un nivel básico constituye un elemento de su segmentación como mano de obra, condicionando su capacidad y forma de acceso al mercado de trabajo.

La escuela como transmisora tanto de conocimientos de tipo instrumental, como de un sistema de valores que conforman las expectativas individuales, constituye así un elemento en la crisis de los valores rurales más tradicionales y menos adaptables a las nuevas condiciones sociales y económicas. El mayor nivel educativo ha actuado siempre así, como acicate para la búsqueda de nuevas oportunidades laborales y sociales y ha alentado las expectativas migratorias de las y los jóvenes. Los estudios realizados sobre la transformación social y laboral de la mujer rural han dejado constancia que en las últimas décadas hay una visible desvinculación femenina de la agricultura, en general, y de la familiar, en particular, poniendo mayor acento las generaciones jóvenes de mujeres rurales en nuevas estrategias migratorias, escolares, matrimoniales y, fundamentalmente laborales. 
Queda claro que la sociedad rural abandona sus ancestrales normas de organización, en la medida que se ve influenciada por la sociedad urbana. Es en este contexto en el que, particularmente las mujeres rurales están adquiriendo nuevos roles en sus familias, tal es el caso de las trabajadoras jóvenes de la zona de estudio, a lo que se podría agregar que, son mujeres las que participan cada vez más en las migraciones a escala nacional.

Sin embargo, la feminización del empleo rural se hace, al igual que en la ciudad, a costa del incremento del trabajo de las mujeres, que se ven obligadas a tener un empleo y también seguir cumpliendo sus responsabilidades del hogar. No obstante, es también evidente que esto les abre nuevos derroteros para salir de la dominación patriarcal y tomar decisiones sobre su vida, ya que su nuevo estatus, como trabajadoras asalariadas les abre nuevas posibilidades de participación como jefas de familia.

El funcionamiento de la unidad de producción campesina se transforma tanto por los efectos de la ampliación de la migración, como por la pluriactividad. Con la pérdida de la centralidad de la tierra $y$, fundamentalmente, con los cambios en el empleo, ha cambiado la dinámica de la familia en la toma de decisiones, particularmente por la influencia de los miembros que aportan ingresos propios por su empleo, tal el caso de las mujeres asalariadas.

$\mathrm{El}$ ascenso de las mujeres como sujetos activos (trabajadoras asalariadas) es un aspecto fundamental en las transformaciones rurales, sin embargo, al igual que en la ciudad, su incorporación al trabajo asalariado se realiza en condiciones extremadamente desventajosas, caracterizadas por su eventualidad, flexibilidad, informalidad, desigualdad salarial respecto a los hombres y menores niveles de calificación ocupacional, a los cual cabe agregar que su participación en le vida social y política queda todavía rezagada.

La desagrarización productiva y del empleo, en general y, en particular, del empleo femenino, ha traído adicionalmente una transición de estilos de vida que en el pasado giraban en torno a una ruralidad articulada por actividades agropecuarias hacia su actual reacomodo, en que la diversificación de actividades asalariadas son las que ordenan y dan sentido a la vida y reproducción de las familias y comunidades. La llamada "pluriactividad», como contraparte de la desagrarización, caracteriza lo que se llama «Nueva Ruralidad».2

El análisis de las transformaciones rurales en la población, especialmente de las mujeres jóvenes asalariadas, permite entender las articulaciones, interpretadas como transiciones y/o como oposiciones entre lo rural y lo urbano, entre lo agrícola y lo urbano-industrial.

Finalmente, se plantea una reflexión a cerca de la manera en que el desarrollo desigual del capitalismo en las sociedades locales nacionales y latinoamericanas condicionan los requerimientos de acumulación del capital que, a su vez, contribuyen a la constitución y conservación de diversas formas de reproducción de la fuerza de trabajo. Uno de los más importantes efectos de la sociedad rural de la zona de estudio (Lambayeque, Motupe) puede ser la consolidación de estrategias en la formación del ingreso familiar mucho más dúctiles, con énfasis en la pluriactividad de los hogares rurales, para satisfacer las necesidades básicas, en donde el trabajo asalariado es importante, aunque no única fuente de ingresos.

\section{Tiempos de trabajo}

El tiempo de la doble jornada de las mujeres asalariadas y de la conciliación entre la vida profesional y la familiar, es un problema actual que se manifiesta generalmente en el trabajo de la mujer y que toma connotaciones críticas en el caso de las mujeres rurales, algunas de las cuales realizan adicionalmente trabajos agrícolas, dando lugar a la llamada jornada interminable.

La configuración de los tiempos de trabajo viene produciendo transformaciones que inciden y pesan en la vida personal de los trabajadores, especialmente de las mujeres, originándoles crecientes dificultades en su intento de compaginar los tiempos de trabajo y los tiempos de vida domestica familiar. Dichas dificultades tienen un doble origen: por un lado la prolongación de las jornadas laborales y por otro lado, su creciente imprevisibilidad y variabilidad, que fijan condiciones sociales tendentes a impedir o limitar las posibilidades de que quienes trabajan puedan ocuparse de las tareas que requiere el cuidado de la fami-

2 Barkin 2001. Salas 2011. 
lia. No obstante, esa posible limitación no sería tan drástica de no haberse mantenido la división sexual de actividades consistente en atribuir el trabajo productivo a los hombres y el domestico a las mujeres.

Una gran mayoría $(90.9 \%)$ de las mujeres asalariadas de Motupe trabaja 6 días por semana, respetándose su derecho laboral de un día de descanso por 6 días de trabajo; no obstante una minoría $(9.1 \%)$ de ellas señalan que trabajan los 7 días de la semana, sin descanso. (no se especifica si ello lo establece su contrato o trabajan horas extras). Todas las trabajadoras ingresan a su centro de labores a las 7:00 h. La mayoría de ellas $(70 \%)$ salen del trabajo a las 17:30 h, las restantes salen generalmente a las 19:00 h, La jornada laboral normalmente es de ocho horas con 45 minutos, a la cual se agrega el tiempo de transporte de ida y vuelta al centro de trabajo, que en promedio es de una hora. Para comenzar sus labores diarias estas trabajadoras generalmente se levantan a las 5:00 h, una vez que atienden a su cuidado personal, se dedican a preparar los alimentos del día para su familia, desayuno y almuerzo. La hora a la que se acuestan es a las $21.30 \mathrm{~h}$ (ver cuadro 1$)$.

Cuadro 1

Distribución del Tiempo Diario de Trabajo de la Mujer Asalariada de Motupe

\begin{tabular}{|l|c|}
\hline Actividad & Duración / horas \\
\hline Trabajo asalariado $^{*}$ & $08: 45$ \\
\hline Transporte a centro de trabajo & $01: 00$ \\
\hline Descanso $^{* *}$ & $07: 30$ \\
\hline Cuidado del Hogar & $03: 45$ \\
\hline Cuidado personal & $01: 00$ \\
\hline Alimentación y ocio & $02: 00$ \\
\hline \multicolumn{1}{|c|}{ TOTAL } & $24: 00$ \\
\hline
\end{tabular}

* Hora de ingreso al trabajo: 7:00 h. Hora de salida del trabajo: 17:30 h.

** Hora a la que se acuesta: 21:30 h. Hora a la que se levanta: 05:00 h.

La ocupación de las mujeres durante los días que no hacen trabajo asalariado se distribuye entre un $66.7 \%$ que se dedica a la casa y/o a los hijos, $30.3 \%$ de ellas ayuda en el campo y al cónyuge. Un sector pequeño de $3.0 \%$ de refieren dedicarse al estudio.

Las mujeres que viven en pareja, manifiestan que su actividad profesional ha hecho que la compaginación entre los tiempos de trabajo asalariado con los de cuidados domésticos familiares constituye una dificultad. Se ha podido constatar que la mayoría de trabajadoras entrevistadas se quejan sostenidamente de lo complicado, desigual y hasta imposible que les es compaginar los mismos. Disponen de menores márgenes de tiempo para sus propias necesidades en sus distintas variables, se encuentran atrapadas en una red tupida de obligaciones dictadas por su situación en el mercado de trabajo, pero sobre todo, por la especifica conformación histórica de las relaciones de género, que siguen asignando a las mujeres un cuasi monopolio de las tareas doméstico-familiares, con independencia de su situación en el mercado del trabajo extradoméstico.

La falta de simetría en el seno de la familia conduce a incrementar el tiempo que dedican a las tareas domésticas. La mujer seguirá encontrando mayores dificultades para entrar y moverse en el mercado laboral y pagará una alta factura en forma de apresuramiento, sensación de falta de tiempo y agobio. Sin embargo el proceso de incorporación de la mujer al mercado laboral avanza. Es más, la evolución descendente de la tasa de desempleo femenino parece indicar que tal incorporación viene siendo más atractiva. El ámbito de los tiempos de empleo, que en su expresión jurídica es el tiempo de los contratos laborales, es el espacio social donde hunde sus raíces mas consistentes el problema de la inseguridad social, originada por la inestabilidad y temporalidad del empleo (Bouffertique y Boutelier, 2002).

Trabajo y cuidados domésticos son dos actividades que a pesar de ser insustituibles y necesarias, en tanto que son actividades de producción y reproducción, solo pueden darse a la vez en el tiempo. La simultaneidad se hace imposible cuando ambas actividades ha de realizarlas una misma persona, el problema de la articulación del trabajo y el cuidado se convierte en un problema social. La incorporación de la mujer al trabajo asalariado agudiza la problematización de la temporalidad de las relaciones interinstitucionales: Si el estudio de los tiempos sociales $y$ de su entramado adquiere especial relevancia en momentos en que las sociedades viven grandes transformaciones en la organización de sus actividades de trabajo y de cuidados y en la definición de sus sujetos (hombre-mujer) debido a los problemas de coordinación social que originan, no hay duda que el presente es uno de esos momentos. 
La totalidad de las mujeres encuestadas tienen como ocupación principal la de obreras de agroindustrias, de las cuales cerca del $60 \%$, predominantemente convivientes, casadas y viudas, refieren tener como ocupación secundaria la de amas de casa, que en promedio tienen en total 3.5 hijos y 1.9 hijos residentes en el hogar.

La edad es determinante diferenciando el uso del tiempo, generando categorías con peculiaridades temporales muy marcadas. Las jóvenes dedican menos tiempo de trabajo a las tareas domésticas. Es perceptible así un relativo nivel de satisfacción de las mujeres con el trabajo que realizan en las empresas agroindustriales de Motupe. Un sector de 52.9\% señala que su trabajo no les ocasiona problemas en la distribución de sus tiempos en actividades fuera del trabajo, sin embargo, es notable el otro sector de $47.1 \%$ que afirma afrontar problemas y dificultades. Un 73.4\% de estas últimas explican su situación refiriendo que tienen dificultades para ajustar sus tiempos en los quehaceres del hogar y otro $26.6 \%$ afirman que sus hijos quedan solos. Entre las mujeres que afrontan tales problemas, un $53.3 \%$ refieren que reciben ayuda de sus padres y familiares para dejar a sus hijos, $33.3 \%$ recibe ayuda del conyugue y $13.3 \%$ indica que debe levantarse más temprano para ayudar a sus hijos en las tareas escolares.

Es relevante el grado de satisfaccion y conformidad que las mujeres trabajadoras manifiestan respecto a su trabajo asalariado en las agroindustrias locales, incluidas aquellas madres de familia que afrontan dificultades para compaginar sus tiempos de trabajo y los de cuidados familiares. Una mayoría absoluta de 91.2\% refiere gustarles y sentirse satisfechas con dicho trabajo. Por otro lado, hay un margen de $8.8 \%$ de mujeres que reportan sentirse indiferentes en dicho aspecto.

Las pautas de trabajo flexibles y horarios de trabajo variables, turnos cambiantes, extensiones de la jornada de trabajo, todo ello bajo una creciente inseguridad en cuanto a la duración, renovación del empleo y relación laboral. En dicho contexto, la relación con el espacio doméstico, el encaje de los tiempos laborales genera tensiones, tareas heroicas y, a veces, imposibles. Pareciera que mientras el tiempo de trabajo asalariado es fluctuante, en el caso de las mujeres rurales el tiempo que dedican al hogar es rígido y constante.
Los domingos y feriados son días en que la mujer asalariada dedica más tiempo a las tareas doméstico familiares y actividades tales como las de ayuda en tareas agrícolas y crianza de animales menores y, algunas de ganado. Resulta así que, la mujer trabajadora dedica el fin de semana para compensar su dedicación al hogar, pudiendo hacer así lo que es imposible realizar los días en que trabaja en la fábrica.

Las trabajadoras con poco tiempo libre para sí a lo largo de la semana y sometidas a doble o triple requerimiento temporal de trabajo extradoméstico, trabajo doméstico y trabajo en la parcela familiar, vive una situación estructural de escasez de tiempo. La falta de simetría en el seno de la familia lleva a un incremento del tiempo dedicado a las tareas doméstica y la correspondiente limitación del tiempo de ocio y de cuidados personales. La presencia de hijos dependientes en el hogar hace todavía más escaso el tiempo disponible de las mujeres rurales, en general, pero en forma dramática en el caso de las trabajadoras, sometidas estructuralmente a una doble jornada de trabajo. La mujer campesina seguirá enfrentado mayores dificultades para ingresar, mantenerse y moverse en el mercado laboral y, si lo consigue, pagará una alta factura en la forma de apresuramientos, sensación de falta de tiempo y agobio.

La transformación de la configuración social de los tiempos de trabajo en las últimas décadas es visible. Este cambio, consiste esencialmente en la sustitución de la pauta general que tendía a homogenizar todas las dimensiones del tiempo de trabajo: cuánto, cuándo, cómo y quienes, a otra en la que se tiende a implantar la heterogeneidad, la diversidad y la variación. El trabajo de campo nos demuestra la realidad de tal diversidad y de algunos procesos que llevan a ella, como la desestandarización de la duración del tiempo semanal de trabajo, que es el más significativo. El empleo asalariado a tiempo parcial no es un contrato jurídicamente normalizado y actualmente empieza a ser normal, particularmente con este sector de mujeres rurales. La variabilidad del cuánto y fundamentalmente de cuándo del tiempo de trabajo ha hecho su presencia, tanto en la diversificación de la cantidad como de los horarios y días de trabajo de la mujer rural.

La variabilidad de lo períodos y momentos es una dimensión del tiempo de trabajo de relevancia para la vida de las trabajadoras rurales, ya que su práctica hace que la configuración del tiempo se convierta en un 
ejercicio difícil y complejo y hasta conflictivo. Es decir, se está produciendo un proceso de diversificación del tiempo de trabajo, de ampliación del uso laboral y de variación, de lo que se ha dado en llamar flexibilización general del tiempo de trabajo, la misma que se deriva de la incertidumbre económica a la que hacen frente las empresas ante la globalización de la economía, haciendo que sus prácticas flexibilizadoras se ven facilitadas por el desempleo, actualmente uno de los problemas más visibles en nuestra sociedad. Así pues, no solo se vive un proceso en el que cambian las horas y los horarios de trabajo, sino que además, ese cambio se produce en condiciones de empleo que debilitan la posición de las trabajadoras. Aunque los cambios en la organización del trabajo afectan a todos los trabajadores, no afectan por igual a hombres y mujeres, derivándose el problema de la conciliación, articulación, compaginación y armonización de los distintos tiempos sociales que debe realizar la mujer trabajadora.

El trabajo extradoméstico tiene para la mujer valores distintos, se constata, en general, que limita el tiempo que le demanda la necesidad de compaginar ese tiempo con el que requiere el hogar y la familia campesina. Como que las mujeres trabajadoras estuvieran atrapadas en un círculo vicioso que desemboca en una típica situación de doble vínculo: Culpables y malas madres, si trabajan, porque no podrán brindar su tiempo a los hijos, pero también culpables y malas madres, porque si no trabajan, no dispondrán de los recursos que necesitan. El problema de la articulación de los tiempos de trabajo y la familia está cargado de dramatismo y, en el caso de las asalariadas rurales, es más difícil, porque muchas de ellas también realizan actividades agropecuarias. Si bien se trata de un problema que afecta a todos, especialmente afecta a la mujer, ya que los modelos tradicionales siguen vigentes, eximiendo a los varones de las tareas familiares, asignándoselas a las mujeres.

En definitiva, es claro que el discurso de la articulación y la compaginación es mucho más complejo. Lo que en las estrategias de compaginación se pone en juego, no es solo acabar con la lógica del sacrificio, sino también redefinir las condiciones materiales e institucionales (privadas y públicas) y los modelos morales. Para estas trabajadoras rurales se torna difícil la regulación del tiempo de trabajo en función de las dificultades propias de la conciliación entre la vida laboral y la vida familiar, siendo un trabajo instrumen- tal, situado en las escalas salariales más bajas y prácticamente cerrado a cualquier posibilidad de ascenso.

El trabajo de domingos y feriados separa a las trabajadoras de las vidas y los tiempos de trabajo normales, limitando su ocio, su vida familiar, su descanso; las convierte en "parias temporales» (Ramón Ramos). Estas trabajadoras sintetizan el dramático problema de sincronizar el trabajo asalariado y el doméstico, y en algunos casos, el trabajo en el campo. Expresan una sensación de culpa por la falta de tiempo; algunas recurren a otras personas para el cuidado de los hijos menores.

La difícil y a veces imposible conciliación se expresa en culpabilidad por desatender a los hijos, a la familia, al hogar. Pero al mismo tiempo, el trabajo es percibido por estas mujeres como una importante fuente de ingresos, como un espacio de autonomía personal y de apertura al espacio público. Los tiempos de trabajo están cambiando con una experiencia profunda y a veces traumática para la mujer trabajadora, propia de la sociedad moderna, un despliegue de la realidad social que se expresa cambiante, contingente, frágil y provoca incertidumbre y desconcierto.

Ningún tiempo social es inteligible en sí mismo, sino solo en el marco de sus relaciones con los otros tiempos. Pero hay dos tiempos que actúan como pivotes: el tiempo del trabajo y el tiempo de los cuidados doméstico familiares. Las relaciones de género brindan una de las claves ineludibles para ser inteligibles los cambios sufridos por los tiempos,

La evolución de la tasa de actividad femenina, el salto que han dado al trabajo las mujeres rurales (desagrarización y salarización) y su creciente acceso al empleo temporal y a tiempo parcial, con mayor frecuencia que los hombres, es indicativo que las mujeres trabajadoras no solo han continuado en su intento de trabajar como asalariadas, sino que han multiplicado su empeño; todo esto prueba objetivamente que su apuesta por convertirse en trabajadoras va muy en serio, optando por desembarcar en el mercado de trabajo y quedarse en definitiva.

No obstante, los procesos de segmentación social, en general, y del mercado de trabajo, en particular, solo se comprenden si además de atender a las transformaciones que se están sucediendo en el tiempo de trabajo, tenemos en cuenta los cambios que se están dando en el tiempo doméstico familiar.

Se establece una clara tendencia de los procesos de cambio social actuales hacia una cada vez mayor se- 
paración, entre los espacios del trabajo y del hogar. Si bien se trata de una separación ambivalente y paradójica, se trata más de un proceso de individualización; la separación se desdibuja sin llegar a negar la tradicional dependencia entre el espacio laboral y el espacio doméstico familiar. En esta nueva dependencia el tiempo aparece como responsable y revelador del mundo emergente; el tiempo de trabajo laboral en sí, se erige en variable central a la hora de compaginar los espacios en que se articulan el trabajo y el hogar.

Las mujeres tienden a expresar posiciones críticas frente a los cambios que viene sufriendo la organización del tiempo de trabajo, actualmente de mayor calado y de mayor intensidad que en el caso de los hombres. La nueva situación de las mujeres, de doble presencia y doble actividad, está modificando sustancialmente el modo de plantear la cuestión del trabajo. Lo que está en juego no es la compaginación de unas actividades concretas realizadas por agentes concretos, que son mujeres, sino la compaginación de dos esferas de actividad social, las de producción y reproducción, ambas imprescindibles para la sociedad.

Son crecientes las dificultades que encuentran los trabajadores, particularmente las mujeres asalariadas, para compaginar sus tiempos de trabajo y sus tiempos de vida doméstica familiar. Dificultades que tienen un doble origen, por la prolongación de las jornadas laborales y su imprevisibilidad y variabilidad, que fijan condiciones sociales que impiden o limitan la posibilidad que quienes trabajan puedan ocuparse de tareas para el cuidado de la familia.

Desde los años 90 a la actualidad, en que se instalan las empresas agroindustriales en Lambayeque, la temporalidad del trabajo ha pasado a jugar un papel importante en la delimitación del mercado de trabajo, situación que no se daba anteriormente. Las tendencias de cambio en la organización y configuración actual de los tiempos de trabajo de las mujeres estarían condicionadas por los cambios en la concepción integral del entramado social, como es la desagrarización del empleo en la zona, propiciada por la creciente actividad agroindustrial en la región.

En su despliegue institucional, el cuánto, el cómo y el quién del trabajo, tendrá que encontrarse en su doble sentido, de coincidir con este y de enfrentarse con el de los cuidados de la institución doméstica, chocan así los tiempos de las dos instituciones, que entran en conflicto al coexistir y que sin embargo han de hallar el modo de compaginarse, conciliarse.

El punto más visible en la problemática actual del tiempo de trabajo y de su articulación con el doméstico-familiar es el resultado del encuentro de dichas dos tendencias y los problemas que suscitan. Por un lado el tiempo de trabajo ha entrado en una fase total de flexibilización en todas sus dimensiones y el tiempo doméstico familiar, al igual que el resto de tiempos sociales, se ve sujeto a más exigencias de adaptación y subordinación que limitan su autonomía.

Por otro lado, la mujer ha abandonado su posición tradicional en el seno de la institución familiar $y$ se ha incorporado al trabajo como una actividad normal, lo que ha alterado y problematizado las relaciones familiares tradicionales, ambas cuestiones interactúan de modo que las exigencias de disponibilidad originada por la flexibilización del tiempo de trabajo agudiza la problemática de la temporalidad en las relaciones de género.

La variabilidad de las cantidades y de los momentos de trabajo es una dimensión del tiempo de trabajo de importancia para la vida de las trabajadoras asalariadas, ya que su práctica hace que la compaginación de sus tiempos de trabajo se convierta en un ejercicio complejo, difícil, y hasta conflictivo. Es decir, se está produciendo un proceso de diversificación, ampliación del uso laboral, un proceso de flexibilización (cuánto de trabajo en la agroindustria y cuánto en las actividades doméstico familiares), se ha desagrarizado y urbanizado el empleo femenino rural.

La flexibilización general en los términos del trabajo y, en particular, en el tiempo de trabajo, que se viene implantando en país hace más de veinte años, tiene que ver con el proceso de la globalización y la incertidumbre económica a la que deben hacer frente las empresas agroindustriales, mientras que éstas han visto facilitadas sus prácticas flexibilizadoras por el cambio en su correlación de fuerzas ante el ingreso de las mujeres en el mercado de trabajo.

Así pues, no solo se vive un proceso en el que cambian las horas y horarios de trabajo, sino que además ese cambio se produce en condiciones sociales de empleo que en términos generales, debilitan la posición de las trabajadoras rurales y fortalecen la situación de las empresas. Asimismo, es previsible poder demostrar que las proporciones de contratados a tiempo parcial son mayores en el caso de las mujeres 
y posiblemente también sean las mujeres las que más trabajan los días feriados, sábados y domingos. Es decir, si bien los cambios en la organización del tiempo de trabajo afectan a todos los trabajadores, hombres y mujeres, no afectan por igual a todos.

La compaginación de los tiempos de trabajo y los de cuidados familiares por parte de las mujeres rurales es problemática, siendo lo central la relación del tiempo de trabajo y el tiempo familiar, la distribución de las actividades y sus tiempos se complejiza en su interrelación, formando un complejo enmarañado e indiferenciado.

El problema en la configuración del tiempo por la trabajadora es si ella ha de incorporarse al trabajo asalariado es porque necesita ganar dinero, en el hogar en términos generales, el salario es siempre necesario, entonces, el problema es cómo disponer del tiempo para la realización de las labores domésticas. Se trata de un sector de mujeres que afronta el problema de la regulación del tiempo de trabajo, en función de las dificultades propias de la conciliación entre la vida laboral y la vida familiar, desempeñan un trabajo instrumental situado en las escalas salariales más bajas y prácticamente cerrado a cualquier posibilidad de ascenso profesional. Así se tornará difícil y hasta imposible la sincronización de los tiempos de trabajo con los tiempos personales y familiares.

Hay un planteamiento adicional relativo a las trabajadoras rurales en la agroindustria, en lo referente a que dicha actividad les permite una socialización más viva respecto al trabajo dentro del hogar. El trabajo le permite expandir el espacio social abierto a la mujer, rescatándola de su exilio doméstico y ampliando sus relaciones sociales. La mujer, que en su versión tradicional es un ser de dentro se convierte gracias al trabajo asalariado en un ser de fuera. El trabajo para la mujer rural genera una ampliación de su esfera de acción, una independencia, una capacidad para valorarse por sí misma y tener mayor autonomía, es evidente sin embargo, que esa independencia arrastra servidumbres, en gran parte, dictadas por el rol de la mujer como madre-ama de casa y por el espacio rural de donde procede.

Desde el punto de vista de las condiciones personales y las identidades sociales, se puede distinguir tres categorías generales de mujeres trabajadoras: 1) Madres de familia, para las que el trabajo supone tanto un complemento del ingreso familiar impres- cindible, como también una constante fuente de complicaciones a la hora de compaginar trabajo asalariado y trabajo doméstico familiar. 2) Trabajadoras para las que el trabajo asalariado representa una primera vía de acceso al mundo laboral, en razón de su juventud, logran el tránsito del espacio doméstico al salarial y 3) Trabajadoras jóvenes que compaginan estudios con periodos cortos de actividad laboral (fines de semana-verano-vacaciones) y para las que el trabajo asalariado representa una actividad temporal y no una etapa necesaria e indefinida.

Finalmente pareciera como si el tiempo de trabajo y de vida de las trabajadoras rurales dejara de pertenecerles «queremos estar en todos los sitios y no podemos abarcarlo todo", salir de casa, realizarse fuera del entorno familiar, realizar actividades con otros, son expresiones que aparecen como los referentes que les permiten vivir el trabajo positivamente, como un lugar que dota de independencia, de identidad individual, pero también y fundamentalmente social, les abre el espacio público.

Aunque la división del trabajo en el seno de los hogares está diluyendo la rígida distribución de tareas entre varones y mujeres, las mujeres actualmente, a diferencia de los varones, tienen como referencia tanto el tiempo de trabajo remunerado como el tiempo de trabajo doméstico, subsistiendo todavía un porcentaje significativo de mujeres cuyo tiempo de referencia es exclusivamente el doméstico.

La lenta transformación de la división sexual del trabajo ha permitido a muchas mujeres sortear su asignación prioritaria propia del trabajo asalariado. Resultan las dos caras de la misma moneda en un momento en el quelos procesos de segmentación social están viéndose claramente modificados, reflejándose en cambios en la configuración de los tiempos del trabajo y la vida de las poblaciones, el proceso acelerado de la desagrarización y desruralización del tiempo de trabajo femenino.

Se establece una clara tendencia de los procesos de cambio social actuales hacia una cada vez mayor separación entre los espacios de trabajo y del hogar. Si bien se trata de una separación paradójica y ambivalente, se trata más de un proceso de individualización, la separación sin llegar a negar la tradicional relación de dependencia entre el espacio laboral y el espacio doméstico familiar. 
En conclusión, lo que está en juego no es la compaginación de dos esferas enteras de actividades concretas realizadas por agentes concretos que son mujeres, sino la compaginación de dos esferas enteras de actividad social; la producción y la reproducción, ambas imprescindibles para la sociedad.

\section{Discusión}

Los estudios realizados a nivel de Latino América y en menor medida del Perú dan cuenta del crecimiento de actividades productivas y de empleos no agrarios en el medio rural. El presente estudio verifica que el valle de Motupe-Lambayeque constituye un escenario, erigido desde hace tres décadas, de un desarrollo agroindustrial impulsado principalmente por la exportación, generando un espacio para un proceso de desagrarización del empleo, particularmente por la incursión de la mujer rural en el mercado de trabajo asalariado.

El proceso de salarización del empleo de la mujer rural está vinculado más estrechamente a los sectores de mujeres pobres de la pequeña agricultura, de escasos recursos materiales y culturales. Las mujeres, particularmente jóvenes, son impulsadas en la búsqueda de trabajo asalariado como estrategia para mejorar sus ingresos económicos y como una forma de salir del mundo rural agrícola en el cual se han mantenido tradicionalmente, relegadas a labores doméstico familiares y como ayuda no remunerada en el trabajo de campo.

Los resultados obtenidos en la investigación ponen de manifiesto los profundos cambios en la configuración de los tiempos de trabajo de la mujer rural, agudizando la percepción del tiempo problematizado, que se manifiesta en la dificultades para conciliar los tiempos de trabajo asalariado con los tiempos de cuidados familiares así como los que destina como ayuda en el trabajo de campo, y su incidencia en la organización familiar. La ausencia de estudios sobre el tema y en particular de la mujer rural asalariada para el caso peruano, impide una contrastación con la situación prevaleciente en otras regiones del país.

\section{Conclusiones}

La desagrarización del empleo rural femenino asalariado, entendida como el proceso de vinculación la- boral de la mujer rural con actividades económicas no agrarias, tal como sucede con la agroindustria en Motupe, se viene dando en forma selectiva, principalmente en función de los ingresos económicos familiares, nivel educativo de la mujer y su edad. Dicho proceso se desenvuelve en el marco de la economía de mercado, impulsada por el liberalismo económico.

La desagrarización y salarización del empleo constituyen las claves del cambio en las estrategias ocupacionales de la mujer rural de los sectores económicos pobres. En el valle de Motupe-Lambayeque se asiste a una transferencia de mano de obra femenina desde el medio rural agrícola familiar hacia el empleo agroindustrial y otras actividades secundarias y terciarias. La emigración del ámbito rural local en búsqueda de empleo asalariado registra la huida de la condición de ayuda en la unidad agraria familiar hacia el empleo remunerado en una actividad manufacturera industrial asentada en la misma zona.

El arraigo forzoso generador de una reserva de mano de obra femenina elude la situación de aquellas mujeres que, viendo restringidas sus posibilidades de movilidad, pasan coyunturalmente de amas de casa a ser trabajadoras efímeras de la agroindustria, en unidades que se vienen asentando en los márgenes de áreas rurales y que se caracterizan por ser receptoras de mano de obra femenina.

Las trabajadoras asalariadas aprecian el trabajo que realizan como muy importante por ser una actividad que les genera un ingreso propio, a la vez que las independiza en su economía personal y las empodera socialmente, no obstante que los salarios y las condiciones laborales son precarias.

La mujer joven constituye una reserva de mano de obra local, dado que las circunstancias familiares y culturales favorecen los fenómenos de salarización precaria en sectores manufactureros tradicionalmente femeninos, como es el caso de las agroindustrias de frutas y leguminosas.

La distribución de los tiempos de trabajo asalariados y los tiempos de ayuda en el trabajo de campo en la unidad familiar y de cuidados domésticos por parte de la mujer rural asalariada, especialmente de las madres de familia, evidencia una agudización de la doble jornada laboral que afronta la mujer, por las dificultades y conflictos que afronta en la compaginación de sus tiempos, que repercuten en la organización familiar. 


\section{Referencias bibliográficas}

BAECHAN y URDY (2009). Los salarios aumentan y las nuevas trabajadoras enfrentan barreras legales. Citado por Arias, Custodio. «Condiciones de trabajo en el Perú del siglo XXI». Revista de Sociología No 1. UNMSM. Lima.

Banco Central de Reserva del Perú. Gerencia Central de Estudios Económicos (2018). Exportaciones de productos no tradicionales. Lima: BCRP.

Berlam, M. y Paivin, R. (1980). Les conditions de vie et de travail des femmes deus les exploitations agricoles en France. Paris: INRAENSA.

Bouffartique, P. y Bouteelier, J. (2002). L’erosion de la norme du temps de travail et employ. La Revue de PIRES No 92. Paris.

Bourdieu, Pierre (2000). La dominación masculina. Madrid: Editorial Anagrama.

Callejo, Javier (2007). «Temporalidades y tiempo de trabajo: vivencia de trabajadores y trabajadoras». Trabajo, género y tiempo social. Madrid: Ed. Complutence - Ed. Hacer.

Cамасно, G. (2010). Mujeres migrantes: trayectoria laboral y perspectiva de desarrollo humano. Quito: CLACSO.

CARnoy, M. (2000). El trabajo flexible en la era de la información. Madrid: Alianza.

Carrasco, C., Alabart, A., Domínguez, M. y otros (2003). Tiempos de trabajo y flexibilidad. Una cuestión de género. Madrid: Instituto de la Mujer.

Deere, Carmen (2006, noviembre). «¿La feminización de la agricultura? Asalariadas, campesinas y reestructuración económica en la América Latina rural». Revista ALASRU. Nueva Época. Núm. 4. pp. 77-136, México.

Eguren, Fernando (2010). Caso del Perú: politicas de mercado de trabajo y pobreza rural en América Latina. Roma: CEPAL - OIT - FAO.

Eguren, F. y Cancino, I. (1998). Agricultura y sociedad rural en el Perú. Debate Agrario Nos. 29-30. Lima.

García Ferrando, Manuel (1977). Mujer y sociedad rural: un análisis sociológico sobre trabajo e ideología. Madrid: Edicusa.

Giraldo, O. (2010). «Campesinas construyendo la utopía: Mujeres, organizaciones y agroindustrias rurales». Cuadernos de desarrollo rural. PUJ. Colombia.

IAASTD (2008). Informe cientifico. Resumen del informe publicado en 2008 por evaluación internacional de las ciencias y las tecnologías para el desarrollo. IAASTD.
KanAshiro, L. (2014). ¿Quién alimentara el mundo? Una oportunidad para la agricultura familiar del cacao peruano. Conexión ESAN.

Lastarria-Cornhuel, S. (2006). Feminization of agriculture frends and driving forces. Santiago de Chile: RIMISP.

LoAyza, Sulema (2000). «Acceso de la mujer a la tecnología en las economías campesinas». Investigaciones Sociales. Revista del Instituto de Investigaciones Histórico Sociales. Año IV. No 6. UNMSM.

Mejía, Julio (2002). "Trabajo femenino, relaciones de género y agroindustria». Investigaciones sociales. UNMSM.

Organización de Naciones Unidas (2008, octubre). La mujer rural en un mundo cambiante. Nueva York: ONU.

Prieto, Carlos; Ramón Ramos y Javier Callejo (2008). Nuevos tiempos del trabajo. Entre la flexibilidad competitiva de las empresas y las relaciones de género. Madrid: Centro de Investigaciones Sociológicas.

Ramos, R., Prieto, C., Gallego, J. (2008). Nuevos tiempos del trabajo. Madrid: Centro de Investigaciones Sociológicas.

Riveros, H., Lucio-Paredes, A. y Blanco, M. (2009). Una mirada a experiencias exitosas de agroindustria rural en América Latina. San José de Costa Rica: IICA.

SAENGer, C. (2001). Equidad y género en la agricultura sostenible. Lima: Ed. Flora Tristán.

SAN Pedro, Rosario (1996). Género y ruralidad: Las mujeres ante el reto de la desagrarización. Madrid: Ministerio de Trabajo y Asuntos Sociales. Instituto de la Mujer.

SAN Pedro, Rosario (2012). La pluriactividad en el campo latinoamericano. Quito: FLACSO.

Trivelli, C. y Smith, S. (1997). Cultivos andinos y el mercado. El caso del ulluco en la Sierra Sur del Perú. Lima: CIP-IEP.

Yamada y Chacaltana (2009). Evolución del empleo de cultivo y actividades de agroexportación. Citado por De León Castillo, Yanina en Economía y Sociedad No 73. CIES-PUCP. Lima.

Whatmore, Sarah (1988). ¿Ciclo vital o patriarcado?. Cambios en la división del trabajo en la explotación agraria por razón de sexo. Ponencia presentada al VII Congreso de Sociología Rural. Bolonia. 